\section{Finger Agnosia}

John E. Mendoza

Department of Psychiatry and Neuroscience, Tulane Medical School and SE Louisiana

Veterans Healthcare System,

New Orleans, LA, USA

\section{Definition}

Inability to distinguish or identify individual fingers of the hand. It is operationally defined by asking the patient to either name individual fingers or to point to fingers named by the examiner.

\section{Current Knowledge}

If finger agnosia is truly present, the deficit is expressed bilaterally and includes an inability to name or identify fingers belonging to the examiner. Finger agnosia represents a special (and most common) case of autotopagnosia, an inability to name body parts, or more generally, a disturbance of body schema. Especially vulnerable are the three middle fingers, the thumb and little fingers tending to be more accurately identified. The disorder must be distinguished from more basic disturbances such as unilateral neglect, anomia, a unimodal perceptual deficit, or generalized dementia. If associated with difficulties in right-left discrimination, calculations, and writing (Gerstmann's syndrome), there is a high probability of a lesion involving the angular gyrus of the left or dominant hemisphere. There is some evidence that finger agnosia is associated with degree of certain cognitive deficits in individuals with Alzheimer's disease.

\section{Cross-References}

Autotopagnosia

Body Schema

Gerstmann's Syndrome

\section{References and Reading}

Benton, A. L. (1959). Right-left discrimination and finger localization. New York: Hoeber-Harper.

Davis, A., Trotter, J., Hertzaq, J., Bell, C., \& Dean, R. (2012). Finger agnosia and cognitive deficits in patients with Alzheimer's disease. Applied Neuropsychology - Adult, 19(2), 116-120.

Denburg, N. L., \& Tranel, D. (2003). Acalculia and disturbances of body schema. In K. Heilman \& E. Valenstein (Eds.), Clinical neuropsychology (4th ed., pp. 161-184). New York: Oxford University Press.

Kinsbourne, M., \& Warrington, E. K. (1962). A study of finger agnosia. Brain, 85, 47-66. 